\title{
Development and Deployment of NASA's Budget Execution Dashboard
}

\author{
Peter Putz \\ Universities Space Research Association \\ NASA Ames Research Center \\ Moffett Field, CA 94035 \\ 650-604-2137 \\ pputz@riacs.edu
}

\begin{abstract}
This paper discusses the successful implementation of a highly visible company-wide management system and its potential to change managerial and accounting polices, processes and practices in support of organizational goals. Applying the conceptual framework of innovation in organizations, this paper describes the development and deployment process of the NASA Budget Execution Dashboard and the first two fiscal years of its use. It discusses the positive organizational changes triggered by the dashboard, like higher visibility of financial goals and variances between plans and actuals, increased involvement of all management levels in tracking and correcting of plan deviations, establishing comparable data standards across a strongly diversified organization, and enhanced communication between line organizations (NASA Centers) and product organizations (Mission Directorates). The paper also discusses the critical success factors experienced in this project: Strong leadership and division of management roles, rapid and responsive technology development, and frequent communication among stakeholders.
\end{abstract}

\section{TABLE OF CONTENTS}

1. INTRODUCTION.

\section{ORgaNIZATIONAL OBJECTIVES AND TECHNOLOGY}

REQUIREMENTS

3. IMPLEMENTATION RESULTS ......................................................... 3

4. CRITICAL SUCCESS FACTORS ................................................. 3

5. IMPROVEMENTS FOR YEAR 2 ...................................................... 5

6. DISCUSSION ...................................................................................... 5

REFERENCES ......................................................................................... 6

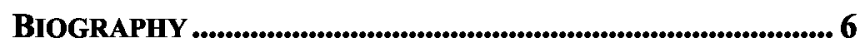

\section{INTRODUCTION}

This case study describes the successful implementation of a high-level financial reporting system at NASA called the Agency Budget Execution Dashboard (ABED). The author-who has been actively involved in deploying and operating this system as a project lead for one of the two underlying technologies-hopes that this study provides insights and lessons learned about the enablers and critical success factors which are applicable to the implementation of other large scale management systems.

\footnotetext{
${ }^{1}$ 978-1-4244-2622-5/09/\$25.00 C2009 IEEE.
}

In November 2007 NASA's newly appointed Chief Financial Officer (CFO) approached the local CFOs at the Johnson Space Center (JSC) and the Ames Research Center (ARC) to explore the possibility of building an integrated agency-wide financial dashboard. While the JSC team agreed to deliver a web-based interface to display high-level "traffic light" indicators for tracking performance variances of Space Missions and NASA Centers, the ARC team was mandated with collecting all Agency phasing plans, processing financial actuals, and delivering monthly reports showing plans versus actuals charts.

The two teams were contacted because they had created technologies in the past, which seemed to be feasible to create the ABED. The JSC team had built and operated the Integrated Budget Office Toolbox (IBOT), a web-based system to support budget planning and analysis. The ARC team had developed and used the Program Management Tool (PMT), a project management and financial reporting tool suite using spreadsheets as the main user interface [1]. PMT also already had available a reliable connection to NASA's accounting system to access obligation, cost, and workforce actuals.

The two teams completed the development of the ABED within two months, and after only five months, the fully operational dashboard became available to the end users. It was used "officially" as early as mid April 2008 when the Agency CFO conducted the monthly Budget Process Review (BPR). With the completion of this tool, NASA management for the first time in the history of the Agency had access to a single integrated management system to monitor monthly plan versus actual reports for any mission, center or project.

\section{Organizational ObJectives and TECHNOLOGY REQUIREMENTS}

The Office of the Chief Financial Officer (OCFO) implemented the ABED within the broader context of supporting NASA's financial performance goals [2].

The primary objective was to significantly enhance the agency's financial performance in terms of using available funds more efficiently. Historically, NASA had an increasing problem with obligating funds in a timely manner. The amount of un-obligated funds that needed to be 
carried over from one fiscal year into the next surpassed $10 \%$ of NASA's annual budget - a fact that was under close scrutiny by the U.S. Congress and Office of Management and Budget (OMB).

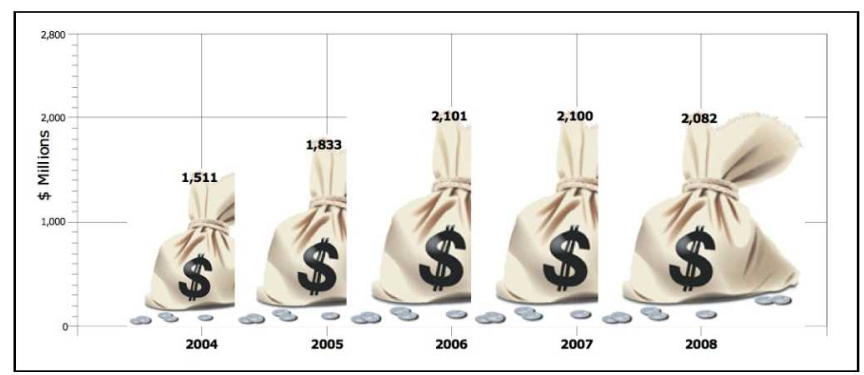

Figure 1 - NASA's Un-obligated Funds [1]

Therefore, the OCFO decided to focus on the near term objective to reduce the amount of un-obligated funds ${ }^{2}$ to less than $\$ 1$ billion in fiscal year (FY) 2008. The ABED was intended to become the single source of reference for monitoring and managing the budget execution process by providing reliable and timely information on cost and obligation plans and on the variances between plans and actuals. The tool should become available to a large number of resources and program executives in the Mission Directorates and Space Centers (that is the 10 major NASA centers nation-wide) in order to enable them to proactively manage their funds.

One challenge for the ABED was to support a single, integrated, comprehensive agency phasing plan process. Before this initiative, NASA had lacked an integrated phasing plan system. Instead, plans were collected locally in the Space Centers and then forwarded to the Mission Directorates. However, the plan numbers differed significantly in terms of quality, content and granularity to the point that plans from different centers could not be aggregated at the agency level. By the same token, mission directorates used different concepts for tracking actual costs (costs vs. total calculated cost). This divergence created serious barriers for managing budget execution goals centrally and agency-wide.

The implementation of a unified phasing plan system and process had to reflect NASA's matrix organization. While the line organizations (Space Centers) were responsible for creating the plans bottom-up, the product organizations (Mission Directorates) were the ultimate owners of the plans, responsible to Congress for their budget execution.

${ }^{2}$ In the accounting system used by the U.S. government the spending of funds is tracked along a four-step budget execution process: (1) Commitments: administrative reservations of funds, (2) Obligations: amounts of orders placed, contracts awarded, services received, or other similar transactions, (3) Costs: services or products received, (4) Disbursements: the final outlay of public money. [3]
Therefore, a multi-step process was implemented that required the Centers and Mission Directorates to interact strongly with each other in order to refine the initial plan submissions.

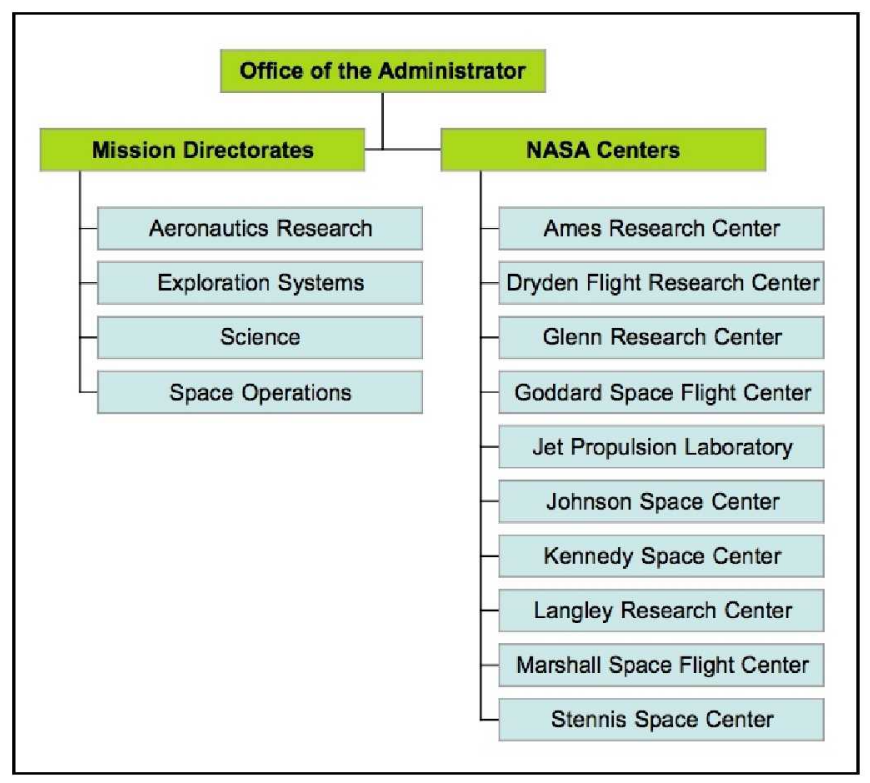

Figure 2 - NASA as a Matrix-Organization

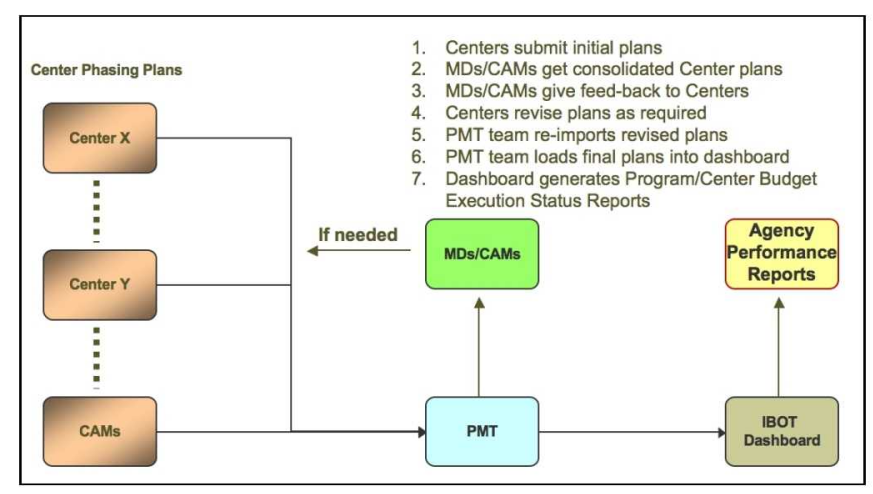

Figure 3 - NASA's Phasing Plan Process [2]

Given the urgency of the organizational objective to reduce un-obligated funds, the ABED needed to be developed and implemented as fast as possible. One approach to accomplish this was to integrate with existing systems. For displaying cost and obligation actuals, ABED needed to connect with the agency's accounting system. For collecting the plan data, ABED needed to accept outputs from existing center systems.

The OCFO decided that it was unreasonable to replace existing center systems since they were well integrated with other management processes such as funds control and various local reporting functions. In addition, leaving the existing systems in place helped minimize time and efforts for training and system implementation. 


\section{IMPLEMENTATION RESULTS}

The ABED was fully deployed on April $14^{\text {th }}, 2008$ only five months after the first conversations with OCFO. It was used as early as April 17th when the Agency CFO conducted the Budget Process Review (BPR). Participants of the monthly BPR were all Deputy Center Directors, Center CFOs, and senior management from all Mission Directorates. Since then, the dashboard reports were not only used for the monthly BPRs, but also for the Agency Management and Operations meetings and monthly Agency Resources Management Performance Reports, which were distributed to staff at each Center, Headquarters Office, and Mission Directorate. For the first time, senior executives and resources managers had a single reference for the agency's budget performance data.

The successful implementation of the ABED was one element that contributed to a remarkable turnaround in NASA's resource management performance. In fiscal year 2008, NASA was able to far surpass its target of reducing the un-obligated funds below $\$ 1$ billion. In fact the agency ended the year with just $\$ 535$ millions of un-obligated funds [4].

\section{Critical Success Factors}

The successful development, implementation, and operation of the ABED was based on a large set of enablers and success factors which can be grouped into three categories-project management, organizational factors, and technology development.

\section{Project Management}

The success of this project was unequivocally due to clearly defined goals and to differentiated leadership roles.

The final deliverable of this project was defined within the first two weeks into the project in November 2007 and it was never changed: "Provide a [Budget Execution] Dashboard to the Agency OCFO by the end of January based on the concepts already in use at JSC along with the inclusion of reports based on Ames' PMT capabilities. The dashboard is a status tool reporting plans, actuals and variances." This definition already implies an implementation strategy that explicitly utilizes existing technology as building blocks of an innovative solution. In the academic management literature, this approach is called bricolage [5]. It refers to an improvisational approach that "makes do with the means or resources at hand" [6]. It was the combination of clear goals and bricolage in the project execution that allowed the project team to deliver a final product within only six months.

Committed project managers and senior executive support are crucial for any large-scale organizational change project. In this case, the agency CFO was the initiator and sponsor of the project. He stayed strongly involved throughout the implementation, and he personally made all decisions over any significant changes in scope or schedule. The CFO took on the role of leading all senior-level discussions with Mission Directorates and center management and enforcing the implementation of ABED throughout the entire organization.

The CFO also mandated the newly assigned director and assistant director of Office of Performance Reporting to facilitate the data collection for the dashboard: in particular, the phasing plan collection. They became the expert facilitators. As outlined above, the phasing plan process was not only essential to the success of the system, but also the most complicated in terms of coordinating hundreds of resource managers throughout the matrix organization. The individual Space Centers were able to continue using their local and familiar tools. However, significant changes in their work practices needed to be made to satisfy the new standardized set of data requests. The Office of Performance Reporting supported this process by developing detailed instructions for the process, schedule and data standards, as well as by facilitating weekly phone conferences, which were open to all participants. These open forums were key to gaining the necessary momentum for overcoming all the obstacles and concerns along the way.

\section{Organizational Factors}

The strongest driver behind the successful implementation was a clear and externally relevant agency goal: namely, to reduce the un-obligated funds significantly (see above). The agency's standing with the U.S. Congress and the OMB was dependent on accomplishing this objective. It was hard to argue that NASA would need more funding if at the same time a large amount of money circulated unused within the agency. The reduction of un-obligated funds provided a strong reason for the Mission Directorates and Space Centers to fully participate in the deployment and use of the ABED.

Strong visibility of the progress towards this goal reinforced the significance of this matter and allowed project and resources managers throughout the agency to take proactive actions as soon as the plan variances surpassed certain critical thresholds. The OCFO defined a unified set of variance thresholds that applied to every Space Center and Space Mission. The thresholds were displayed in the dashboard as so-called "traffic lights", that is as red, yellow, and green color indicators. This method allowed an easy tracking of "red" outliers and facilitated a management-byexception approach, as shown in Figure 4. 


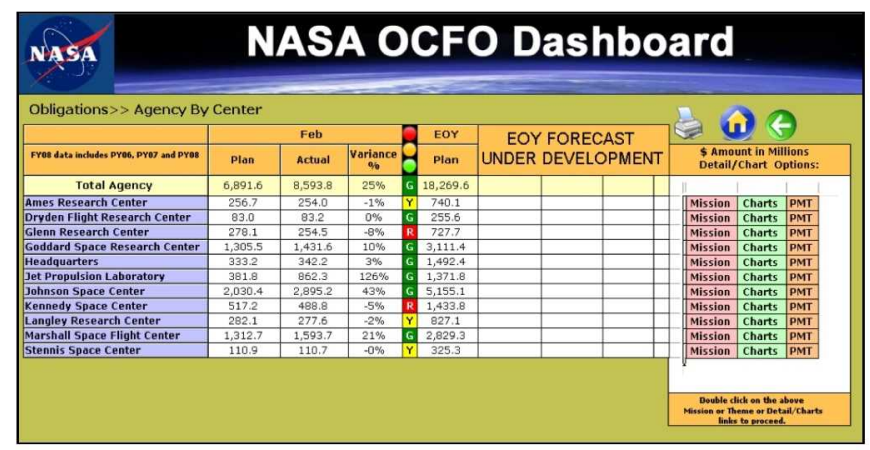

Figure 4 - ABED with "Traffic-Light" Indicators

In addition to the dashboard, which was accessible without restrictions to any resources manager within the organization, the OCFO developed the monthly Agency Resource Management Performance Reports. These publications were (1) issue-oriented (top 10 issues), actionable ("Red" performance areas highlighted), utilizing comparative analysis-evaluation techniques; and (2) focused senior management's attention to performance benchmarks. Broadening the distribution and utilizing the report beyond the OCFO community focused more management attention on budget execution performance than in prior years [4].

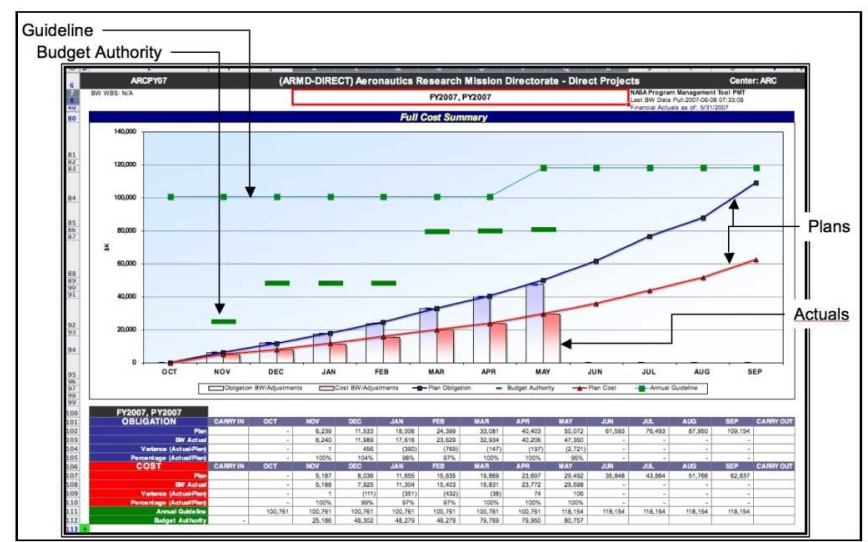

Figure 5 - Detailed Plan versus Actual Reports

The OCFO also initiated a tightly woven communications network by establishing over 70 budget execution and procurement focal points at every Space Center and Mission Direction office. This resulted in a highly effective bottomup campaign directed at ensuring efficient and effective use of all resources during the financial year.

\section{Technical Factors}

The tight development and implementation schedule required a highly flexible technology that could easily connect with existing systems. Conventional relational databases are at a disadvantage because they are schemabased, that is all data is stored in predefined table-spaces, which are relatively hard to change. PMT, on the other hand, uses a 'schema-less' $\mathrm{xml}$ database, that allowed the fully automatic indexing and retrieval of heterogeneous data sources as long as they were formatted as $\mathrm{xml}^{3}$ files[7].

Within two months, a fully functional system prototype was created. PMT was used:

(1) To collect plan and actual cost, obligation and workforce data, from different center planning tools and from NASA's accounting platform Business Warehouse (BW).

(2) To roll up all financial data from the lowest levels (funded projects) to the highest levels (missions) using the agency's work breakdown structure (WBS).

(3) To export data to the web-based dashboard at JSC and to other center systems.

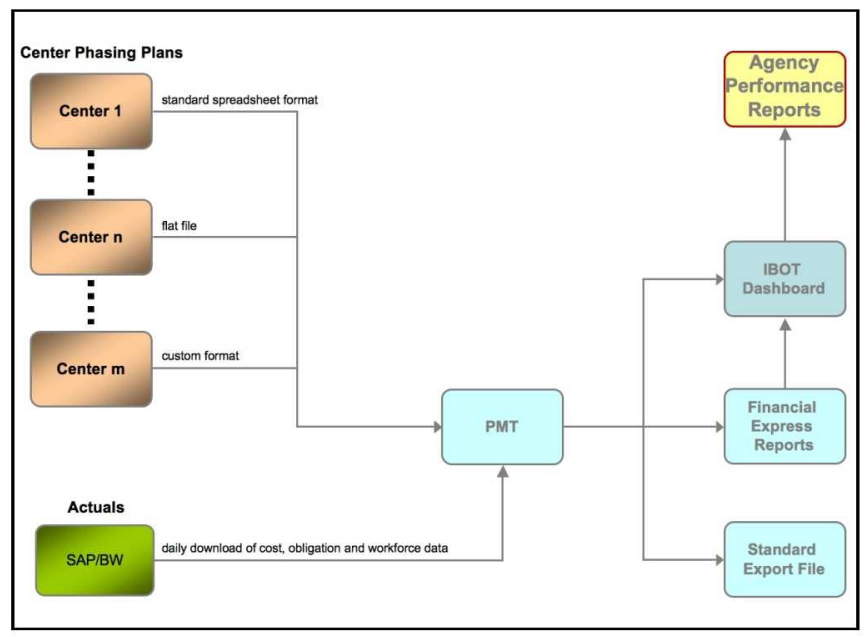

Figure 5 - ABED System Architecture

From a software engineering perspective the PMT team followed an approach know as "agile programming" [8]:

(1) Stakeholder collaboration over contract negotiation: For this project, neither the time nor the organizational consensus was available to develop a comprehensive and complete requirements document (some people argue that such documents are dysfunctional in any case). Rather, the requirements were developed, refined and changed in close interaction with the customers (OCFO) and other stakeholders, especially the Mission Directorates and Space Centers. Data input templates for the phasing plans, report formats, and data exchange formats were iteratively refined as the customers had a chance to review and test working prototypes. Interactions between the development team and stakeholders occurred as needed, often on a daily basis. There was no formal decision mechanismwhatever could be solved on a 'lower' level was just fine-with the one exception that any fundamental

\footnotetext{
${ }^{3} \mathrm{xml}$ stands for Extensible Markup Language
} 
change in schedule or scope had to be approved by the agency CFO.

(2) Responding to change over following a plan: To provide an example, the PMT team collected 1,788 phasing plans from 10 different NASA Centers and Headquarters. The plans were received in four different data formats, and they were edited and refined over three rounds of submittals. Pretty much everything in this process was up-to-last-minute changes. As mentioned above, historically the NASA Centers used very different formats and concepts for their internal plans. As the OCFO strived for a unified standard, the different stakeholders pushed back multiple times requesting changes to this standard. The same thing happened with regard to the file exchange formats since the software teams at the individual Centers also had to respond to moving targets. In such a situation, frequent communication, software test runs, and flexible technology were crucial.

(3) Working software over comprehensive documentation: Development and implementation of the various modules of the ABED were driven forward by the rapid release of fully functional prototypes. This rapidity allowed customers and other stakeholders to get a hands-on experience of the product early on. More often than not, the requirements were refined after this first exposure. This refinement can be framed as a collective learning experience since both customers and developers developed insights that would have been impossible without a concrete product at hand. Ultimately, this hands-on approach led to a high confidence that the developed product would in fact be ready for operational use.

(4) Individuals and interaction over processes and tools: In our experience, in situations of rapidly changing requirements, direct interactions among the individuals of the development team are more efficient and less error-prone than formal processes and tools (such as bug-tracking tools). The PMT core development team consisted of three software developers, one management scientist, one accounting expert, and one customer service representative. This mix of expertise within a fairly small development team made it possible to react quickly to any stakeholder request (whether it was technical or accounting-related in nature) and to interact with each other through personal face-to-face communication.

\section{IMPROVEMENTS FOR YEAR 2}

The lessons-learned from fiscal year 2008 led to three main areas of potential improvements: increase in accuracy of plans, better communication, and capture of commitments as an early warning indicator.
As pointed out above the collection of unified phasing plans was highly successful in 2008. However, a detailed end-ofyear analysis revealed that the plan data for costs were inaccurate. The cost plans predicted that $77 \%$ of funds would be costed by the end of the year when in fact only $71 \%$ were spent. Therefore, the OCFO decided to put special emphasis into encouraging the Centers and Mission Directorates to create performance-based plans rather than simply aligning the plans with average agency performance metrics.

To support this effort the OCFO created a whole bundle of measures:

(1) Each Center received a chart displaying their actual costing pattern for each funded project in 2008. This gave the resource analysts a baseline to work against.

(2) The PMT team created a set of phasing plan "exception reports". These reports were used by the OCFO and the Mission Directorates to review the initial plan submissions. The exception reports highlighted any deltas between the 2008 spending pattern and the 2009 plans. In addition the reports also flagged any other errors and rule violations.

(3) The OCFO provided time guidance for procurements to assist program offices and Centers in estimating the lead times for various types of procurements.

The second area of improvement was the communication between the functional organizations (Centers) and the product organizations (Mission Directorates) to foster joint ownership of the final approved agency phasing plans. A highly interactive process with weekly teleconferences and three video-conferences, supported by enhanced phasing plan tools, was implemented to further open the missioncenter communication during the phasing plan development, review, and approval cycles.

Finally, commitments (see footnote 2) -in addition to obligations and cost - were added to the set of performance indicators. Since the budget execution process starts with committing funds, the level of commitments could serve as an early warning indicator for obligations. In practice, the actual commitments of 2009 were compared to the historic spending pattern of 2008 .

\section{Discussion}

How many large-scale projects were canceled before their implementation even started? Project managers are only too familiar with the traditional model, which starts off with an extensive process of requirements collection. After years of producing large documents, the political situation has changed, the key executives have moved on and the project gets "re-scoped". 
If there was only one lesson learned in this case study, then it is: define a clear goal and keep the requirements collection process as short as possible. Start with the "lowhanging fruit" and use what is at hand and has proven its usefulness (bricolage).

None of the other enablers was particularly new. However, it was the consequent pursuit of a fast and results-oriented implementation that guided project management (executive sponsor vs. expert facilitator), widespread and frequent stakeholder involvement, and a flexible software engineering approach (agile programming).

Finally, a sustainable success can only be accomplished if the system actually gets used in "every-day" management decisions. In this case, the ABED became the single source of reference for any budget execution decision within NASA.

\section{REFERENCES}

[1] A. David Maluf, et al. "The NASA Program Management Tool: A New Vision in Business Intelligence," 2006 IEEE Aerospace Conference Proceedings, March 4-11, 2006.

[2] Glenn Fuller, "OCFO Performance Reporting Initiative," Unpublished NASA-Internal Presentation, April 8, 2008.

[3] NASA Financial Management Manual, "Definitions of Financial Management Terms", FMM 9020, August 2001.

[4] Office of the Chief Financial Officer, "Agency Resources Management Performance Report", Unpublished NASAInternal Report, September 2008.

[5] Claude Lévy-Strauss, "The Savage Mind," Chicago: University of Chicago Press, 1966.

[6] Karl E. Weick, "Improvisation as a Mindset for Organizational Analysis," Organization Science 9, 543555, September 1998.

[7] David Maluf and Peter Tran, 'NETMARK: A Schemaless Extension for Relational Databases for Managing Semi-Structured Data Dynamically," Proceedings of the 14th International Symposium on Methodologies for Intelligent Systems, October 28-31, 2003, 231-241.

[8] Robert C. Martin, "Agile Software Development, Principles, Patterns, and Practices", Upper Saddle River, NJ: Prentice Hall, 2003.

\section{BIOGRAPHY}

Peter Putz is a management scientist with the Universities Space Research Association and Research Institute for
Advanced Computer Science (USRA/RIACS). At the NASA Ames Research Center he is currently the project lead for the NASA Program Management Tool (PMT). Previously he was a member of research staff with the Xerox Palo Alto Research Center (which is now PARC Inc.) where he conducted research on learning and knowledge sharing strategies in the Knowledge, Interaction and Practice Area. Peter received his Ph.D. from the Johannes Kepler University Linz, Austria. There he was an assistant professor with the Department of Business Information Systems and the Department of Management for more then ten years. 
